\title{
Facilities for the school health team
}

\author{
Julie Henshelwood, Leon Polnay
}

\begin{abstract}
Results of a questionnaire returned by 20 doctors giving information of 249 schools showed that many of the rooms made available to school health services are inadequate in terms of physical resources and privacy. A higher set of standards is recommended to enable schools and pupils to derive maximum benefit from community paediatric services.

(Arch Dis Child 1994; 70: 542-543)
\end{abstract}

For a 100 years, school health services have provided a school based programme of child health surveillance, health promotion, prevention of communicable disease, immunisation, paediatric advice to teachers, school based management of medical conditions, and advice on safety in schools to the local education authority. There are important opportunities for counselling, health promotion, and provision of information and resources that will minimise the effects of special needs on the child's ability to learn.

The duty of the local education authority to provide facilities for medical consultation in schools is laid down in the 1977 NHS Act. ${ }^{1}$ Others have also produced guidelines and recommendations, ${ }^{2-6}$ but these have all been basic, often leading to quite unsuitable accommodation being made available. Developments in education such as local management of schools, and the national curriculum, have led to increasing pressure on the use of resources available in schools and a competitive market in terms of how these are distributed. Space or the school health team may be a low priority in comparison with direct educational provision.

Accepted 8 March 1994
Criticism of the resources available in schools to the school health team have led to the widespread use of slogans such as 'school nurses do it in the corridor' or 'school doctors do it in thermal underwear' as a proxy for inadequate rooms and poor heating. This paper investigates the facilities provided to the school health teams by one education authority.

\section{Methods and results}

Questionnaires were sent to all school doctors working in the health authority asking them to answer 10 questions about the medical rooms in each of the schools in which they worked (table). Only 'Yes' or 'No' answers were allowed and two further open questions were also asked. Questionnaires were returned by all 20 doctors giving information on 249 schools.

The results of the two open ended questions were as follows.

Question 1 - How often do you follow up children at the health centre rather than in school and for what reasons do you tend to do this? Frequency ranged from $5 \%$ to $60 \%$ and the reasons given were: (a) where appointments need to be more frequent than the medical sessions at school; (b) to afford a greater degree of privacy (sometimes at parent's or child's request); (c) to allow full examination and tests; (d) to allow more time for a particular child; (e) to supply equipment; (f) to have access to an interpreter; (g) where parents fail to attend at school.

Question 2 - Generally do you feel you are able to provide the necessary quality of care working in schools? Ten respondents said 'No' and four 'Yes'; there was no answer from six. Comments included: (a) a recognition of both the advantages and disadvantages of working in schools; (b) that in one school all medical examinations were conducted at the health centre because of unacceptable facilities in the school; (c) that poor facilities transmit a poor image of the service, lead to a loss of personal and professional self esteem, convey a poor health message, and lead to suboptimal interviews and physical examinations.

Is there a couch for a full abdominal examination?

Can people see into the room?

7 During the interview are you interrupted by:

(a) Telephone ringing

(b) Staff or pupils coming in

(c) Noise in the corridor

8 Do you have a sign on the door to inform people that medical examinations are in progress?

9 Do you feel that the room offers sufficient privacy for:

(a) A medical examination, for example testes check or chest A medical examination, for

(b) A discussion with parents/pupils about sensitive personal issues

10 Does the room at the health centre where you do the school clinic offer greater privacy?

\begin{tabular}{rrr} 
Yes & No & $\begin{array}{l}\% \\
\text { Yes }\end{array}$ \\
\hline 230 & 19 & 92 \\
181 & 68 & 72 \\
219 & 30 & 87 \\
125 & 124 & 50 \\
31 & 218 & 12 \\
95 & 154 & 38 \\
& & \\
69 & 180 & 27 \\
110 & 139 & 44 \\
106 & 143 & 42 \\
89 & 160 & 35 \\
& & \\
138 & 111 & 55 \\
172 & 77 & 69 \\
210 & 39 & 84
\end{tabular}

\section{Discussion}

Our results show not only poor facilities, but also inadequacies in the way that some schools do not respect the privacy of the medical room. We believe this to be a common problem for school health services throughout the UK and indeed in other countries.

Community paediatricians do offer an opportunity to provide health care advice on a wide range of paediatric conditions in a school 
setting. In comparison with an outpatient appointment, the school doctor can provide a service that is very well informed about the child's needs both at home and at school, as well as providing monitoring through the school nursing service thus ensuring the child misses the minimum amount of teaching for that particular appointment. These aspirations cannot be realised in surroundings that fail to convince parents that they are receiving a professional and specialist service.

\section{RECOMMENDATIONS}

We recommend that more specific advice is needed on standards of accommodation for medical rooms at school and how they are used. Rooms should be quiet and private so that conversations cannot be overhead and other pupils or staff should not be able to see into the room. During a medical session the room should be out of bounds to pupils and staff and free from unscheduled interruptions. Rooms should be at least as large as consulting rooms in outpatient clinics or surgeries, warm $\left(65^{\circ} \mathrm{F}\right)$, and their furnishings should provide a relaxed environment in which consultations can take place. Teachers, parents, and pupils need information about the school health services so that the optimum value can be obtained through having a paediatrician visit the school.

1 NHS Act, 1977. (Schedule 1.) London: HMSO, 1977.

2 British Paediatric Association. The school health service. London: BPA, 1987.

3 The Education (School Premises) Regulations, 1981. London: HMSO, 1981.

4 Designing for pupils with special educational needs. London: HMSO, 1992. (Building bulletin 77.)

5 Designing for children with special educational needs in ordinary schools. London: HMSO, 1976. (Building bulletin 61.)

6 Polnay L. Manual of community paediatrics. Edinburgh: Churchill Livingstone, 1988. 